\title{
Are urban parks adapted for the future?
}

Olga MAXIMOVA, The Russian Presidential Academy of National Economy and Public Administration (RANEPA), Russia

\begin{abstract}
The paper analyses how the urban parks can be more adaptive for situation of pandemic. In the era of Covid-19 we are faced new challenges. Weaknesses were and are evident in everyday life also now. Moscow is the largest city in the world situated so far from equator, its agglomeration has a population of 17,2 million people. During the period of pandemic in Moscow from 2nd of April 202055 city parks, estates and recreation areas were closed for visits. The paper discusses how we can change and what we need to change in green infrastructure of urban parks to have healthy accessible territories for citizens also at-risk situation. Should parks be closed during mass infections? What the parks should be like during the period of mass infectious diseases? Which new strategic values can be introduced for development urban green environment of the new generation? Which changes have to be done for urban planning in general, considering innovative approaches?
\end{abstract}

\section{Keywords}

Urban park, Urban forest, Megacity, Pandemic, Moscow

\section{Introduction}

The paper analyses how the urban parks and urban forests can be more adaptive for situation of pandemic. How we can change and what we need to change in green infrastructure of urban parks to have healthy territories and accessibility for citizens also at-risk situation. In the era of Covid 19, we are faced with new challenges. Weaknesses are evident in everyday life now. The ecological framework of the city should be assembled from various elements of the cultural landscape and fragments of the surviving nature. The infrastructure of urban green environment needs to be adaptive for use also at-risk conditions of emergency situation of pandemic to provide possibility to breeze healthy air for citizens.

In many countries during the pandemic the shelter-in-place orders were issued and many public parks and green spaces were closed, in others, where the situation aren't so dramatic, public parks and green spaces remained open for visits, and in third, the streets were temporarily closed to vehicles and transformed for bike- and footpaths.

It is well known that the air in the apartment is 4-6 times dirtier than in the street and 8-10 times more toxic than on the street (Vatin \& Samoplyas, 2004; Zagorskaya, 2014; Odokienko \& Maslova, 2015). About $90 \%$ of infectious diseases and colds are acquired indoors (Vatin \& Samoplyas, 2004). More healthy air is a crucial component for people well-being at every age, but especially for vulnerable populations, for elderly people, for people with cardiovascular diseases and others, for kids etc. What is better: remain at home during emergency situation of pandemic or have the possibility to go out of home to breeze more healthy 
air? Is the air not the primary good and necessity for well-being of everyone also at-risk situation? Those are a very emergency questions have to be discussed.

Should parks be closed during mass infections? What should be the parks during the period of mass infectious diseases? What need we change in our urban parks and urban forests to continue use them, visit them, walk in them, breathe clean air, have healthier environment also in emergency situation of pandemic? Which new strategic values can be introduced for development urban green environment of the new generation? Which changes have to be done for urban planning in general, considering innovative approaches?

\section{Literature review}

Covid-19 have provoked a lot of researches in spatial and urban planning about the possibilities of the cities and its urban environment to be used and to be adaptable during mass infections.

We can define a group of researches which investigate the Impact of COVID-19 on the Sustainable Development Goals (SDGs) (Barbier \& Burgess, 2020; Samuelsson, Barthel, Colding, Macassa \& Giusti, 2020; Kleinschroth \& Kowarik, 2020), focusing on strategies, approaches and policies for future sustainability and development.

Another type related to space policies and COVID-19 dedicated to territorial approach (Ren, 2020), others are about interconnection between urbanisation and pandemics (Lai, Webster, Kumari \& Sarkar, 2020; Megahed \& Ghoneim, 2020). It should be noted that (Hamidi, Sabouri \& Ewing, 2020) spread of pandemic is less facilitated by the density of the hub than by the connectivity of a major urban hub to the surroundings.

The value and urgent need of urban nature during a time of pandemic, its importance for citizens are in the centre of researches worldwide (Hanzl, 2020; Venter, Barton, Gundersen, Figari \& Nowell, 2020; Samuelsson, Barthel, Colding, Macassa \& Giusti, 2020; Xie, Luo, Furuya \& Sun, 2020; Kleinschroth \& Kowarik, 2020; Lopez, Kennedy, \& McPhearson, 2020). It is noted that urban green and large outdoor open spaces can provide residents with a place for safe outdoor activities and social interactions in a green environment during a pandemic and present resilient green infrastructure which value and significance are critical (Lopez, Kennedy, \& McPhearson, 2020).

A series of researches (Samuelsson, Barthel, Colding, Macassa \& Giusti, 2020) shown that natural spaces in the cities should be accessible to the public. The ensuring access to urban nature for the citizens should be a fundamental strategy of cities during overcoming the crisis. The accessibility of the urban nature should be part of the sustainability agenda (SDG 3 (good health and well-being) and SDG 11 (sustainable and resilient cities) (Samuelsson, Barthel, Colding, Macassa \& Giusti, 2020; Venter, Barton, Gundersen, Figari \& Nowell, 2020) as well as maintaining and increasing space for nature in cities.

Another group of researchers are recommendations related to mental and physical health (Hawkley \& Cacioppo, 2010; Cacioppo, Hawkley \& Thisted, 2010; Holt-Lunstad, Smith, Baker, Harris, \& Stephenson, $2015)$ in conjunction with use of public spaces, for example, complex guidelines for parks and green spaces during pandemics (Slater, Christiana \& Gustat, 2020).

Others generation of researches initiates new proposals for design of urban spaces and green spaces, that the innovation ideas (Kleinschroth \& Kowarik, 2020) for new parks have to be implemented according to situation of pandemic. Adaptability of the urban environment should be the basic principle for the urban planning (Danilina \& Vlasov, 2020).

As a common view on the future situation we can mention that the pandemic should influence on future planning (Rice, Mateer, Reigner, Newman, Lawhon \& Taff, 2020; Lai, Leone, \& Zoppi, 2020; Megahed \& 
Ghoneim, 2020) and in the long run the COVID-19 crisis should induce for more sustainable city planning (Samuelsson, Barthel, Colding, Macassa \& Giusti, 2020; Kleinschroth \& Kowarik, 2020) in general and should generate spatial transformations in city planning and city settings (Hanzl, 2020) related to increasing and improving green infrastructure.

\section{Research methodology}

The research investigates the theme of adaptability for future of urban parks and nature in conditions of pandemic, consider the complex analyses of urban planning approaches and policies, regulations during pandemic, urban nature and urban parks management, questions related to design and parks infrastructure, basic values and well-being. The main goal of paper is to investigate the main question: are urban parks adapted for the future?

To achieve those goals has been:

1) studied the contemporary researches in the field of sustainability and development related to COVID19 , urban nature and park policies and recommendations related to COVID-19, value of urban green spaces and green infrastructure, innovation design ideas, sustainable city planning, tendence in spatial transformations, city settings;

2) studied the example of Moscow (considering urban parks and urban nature) as the largest city in the world situated so far from equator with population of 17,2 million people inside its agglomeration.

The basic model of principles has been proposed as basic for urban and spatial planning, management and development of natural spaces and urban parks in the cities.

\section{Case study}

Moscow is the largest city in the world situated so far from equator, its agglomeration has a population of 17,2 million people. Represents the capital of snow agglomerations, where average annual daytime air temperature is $5,8^{\circ} \mathrm{C}$. Moscow is one of the world's megacities. Moscow faces the same problems and challenges of large cities as anywhere else: big waste generator, air pollution, emerging lifestyles in emerging conditions, cultural and social changes, transformation of visual environment, of urban landscape. Also, in the era of COVID-19 Moscow faces the new challenges as everywhere worldwide.

Full review and analysis (Reshetnikov, Mitrokhin, Shepetovskaya, Belova \& Jakovljevic, 2020) of first measures and experience aiming to combat COVID-19 in the Russian Federation conducted between 1 December 2019 and 31 March 2020 defines the needs (5.4.) to revise the following sectors due to people's lives and health risk assessment related to the coronavirus infection: anti-epidemic, administrative, organizational, organizational and technical, medical (in medium term).

The World Health Organization (WHO) officially declared the COVID-19 as a pandemic on 11 March 2020. Due to pandemic in different parts of the world certain rules and measures (more or less strict) were introduced for the use of public places, services and infrastructure related to the induced changes in social distancing, which affected in working environments, human mobility patterns, health and well-being. These restrictions also affected public green spaces.

In Europe different levels of measures were introduced across continent. In Norway the lockdown was not so strict and people had the possibility to spend time outdoors. Analyses of mobile tracking data shown that in Oslo (Norway) recreational use of green spaces increases (by 291\%) during the COVID-19 outbreak (Venter, Barton, Gundersen, Figari \& Nowell, 2020). That reveals the importance of access to green open spaces during the pandemic. Also, in Sweden by introducing soft measures were increased the use of public 
parks and urban nature (Samuelsson, Barthel, Colding, Macassa \& Giusti, 2020). In Berlin we can noticed the increasing of urban space for public use: roads were temporarily closed to vehicles and converted to bike- and footpaths (Kleinschroth \& Kowarik, 2020). In Zurich (Switzerland) the measures were stricter: city parks were closed to the public (Kleinschroth \& Kowarik, 2020).

In United States were issued shelter-in-place orders and many public parks and green spaces were closed. In this case it should be noted the Recommendations for Keeping Parks and Green Space Accessible for Mental and Physical Health During COVID-19 and Other Pandemics (Slater, Christiana \& Gustat, 2020), which proposed short-term and long-term recommendations. One of the short-term recommendations is: "park visits and access to other green spaces could be proactively prioritized and formally organized for vulnerable populations".

Due to the threat of the spread of a new coronavirus infection in Moscow from March 5 a high alert regime was introduced by Decree of the Mayor of Moscow, 05.03.2020, No.12-um. By a lot of amendments were introduced step-by-step restrictions, which led to self-isolation mode. Firstly, citizens who arrived from states (listed) with an unfavourable situation with the spread of COVID-19 were obliged to provide selfisolation at home for a period of 14 days. Then then various restrictions expanded. Restrictions also affected city parks step-by-step.

By the Decree of the Mayor of Moscow of March 25, 2020 N 28-UM "On Amending the Decree of the Mayor of Moscow of March 5, 2020 N 12-UM" were temporarily suspend: leisure, entertainment, entertainment, cultural, physical culture, sports, exhibition, educational, advertising and other similar events with the fulltime presence of citizens in the city of Moscow, as well as the provision of relevant services, including in parks of culture and recreation, shopping and entertainment centres, on attractions and in other places of mass visits of citizens. So, firstly were suspended events in parks of culture and recreation. The first park closed for public was Zaryadye Park (by its administration, March, 25). Then, March 26 other 5 public parks were closed by their administrations: the Gorky Central Park of Culture and Leisure, Park Muzeon, the Tsaritsyno State Historical, Architectural, Art and Landscape Museum-Reserve, Museum-Estate 'Kuskovo', Park of Culture and Leisure 'Sokolniki'.

By Decree of the Mayor of Moscow of March 26, 2020 N 31-UM "On Amending the Decree of the Mayor of Moscow of March 5, 2020 N 12-UM" was prescribed from 28 March to close for citizens the territories of city-wide significance: Exhibition of Achievements of the National Economy, the Gorky Central Park of Culture and Leisure, the Tsaritsyno State Historical, Architectural, Art and Landscape Museum-Reserve, the Kolomenskoye Museum-Reserve, the Zaryadye Park, 'Kuskovo', Park of Culture and Leisure 'Sokolniki'. So, other 2 parks were closed. 2 days early, from March 26 citizens over the age of 65, as well as citizens with diseases (specified in the annex) were obliged to observe the regime of self-isolation.

From 2nd of April by Decree of the Mayor of Moscow of 02.04.2020 N 36-UM "On Amending the Decree of the Mayor of Moscow of March 5, 2020 N 12-UM" it was temporarily suspend to visit 55 areas of city significance: city parks, estates and recreation areas ${ }^{1}$, this provision has been cancelled from $1^{\text {st }}$ June by

\footnotetext{
${ }^{1}$ The list of parks of culture and recreation, museum-reserves, manor museums, public areas closed to the public from April 1 2020: Exhibition of Achievements of the National Economy, Park Babushkinsky, Landscape park Mitino, Park Dzhamgarovsky pond, Park on Olonetsky proezd, Izmailovsky Park, Lilac garden, Park Krasnaya Presnya, Krasnogvardeiskie ponds, Park Kuzminki, Natural and historical park Kuzminki-Lyublino, Recreation area Borisovskie ponds, Park on Borisov ponds, Green area between Shipilovsky thoroughfare and Kashirskoe highway, Park Gardeners, Lianozovsky Park, Goncharovsky Park, Green area of the object Green zone of the river Chermyanki (Ethnographic village Bibirevo), Park Dubki, Park on Angarskaya street, Khodynskoe field, Perovsky Park, Recreation area Terletskaya oak forest, Park at the ponds Rainbow, Victory Park on Poklonnaya Hill, Bauman Garden, Park North Tushino, Zakharkovsky Bay, Recreation area Left Bank, Friendship Park, Park of the Northern River Station, Khimki-2, Sokolniki Park, Tagansky Park, Children's Park. Pryamikova, Fili Park, Park of the 50th anniversary of October, Olympic Village Park, Central Park of Culture and Rest. M.Gorky, Crimean
} 
Decree of the Mayor of Moscow of 21.05.2020 N 59-UM "On amendments to the decree of the Mayor of Moscow of March 5, 2020 N 12-UM". But by the Decree of the Mayor of Moscow of 27.05.2020 N 61-UM "On amendments to the decree of the Mayor of Moscow of March 5, $2020 \mathrm{~N}$ 12-UM" where introduced new regulation ${ }^{2}$ (period 1-14 June) for visit city parks and natural areas (except Park Zaryadye ${ }^{3}$ ). It was allowed only for walks and sports purposes on a special schedule with certain rules: to maintain a social distance; park distance recommendation - $2 \mathrm{~km}$ from residence place; visitors are not entitled to use urban infrastructure facilities, including children's, sports grounds, benches, outdoor pavilions and other objects, objects and equipment with which other persons could contact; the use of personal respiratory protection (masks, respirators).

In Organizational measures aiming to combat COVID-19 in the Russian Federation: the first experience (Reshetnikov, Mitrokhin, Shepetovskaya, Belova \& Jakovljevic, 2020) were indicated the needs to revise and develop architectural planning, construction and household solutions in nearest years. In addition, we can identify that urban planning approaches, standards and technical norms have to be adapted in case of pandemic to have more sustainable urban structures. Approaches for design of green spaces and urban nature norms and standards for planning and design of public spaces, in particularly green spaces and urban nature need to be redefined in direction of sustainability and resilience in pandemic also. Special attention should be paid to the ability to use of green spaces for vulnerable populations.

What do we need to change in our urban parks and urban forests to continue use them, visit them, walk in them, breathe clean air, have healthier environment also in emergency situation of pandemic? If visitors are not entitled to use urban infrastructure facilities, including children's, sports grounds, benches, outdoor pavilions and other objects, objects and equipment with which other persons could contact, firstly, we can indicate the necessity to change the design approach for urban parks and green areas, for its infrastructure. We can define 3 principles for more adaptable park design: (1) less infrastructure, more natural and landscape values, more adaptable spaces, (2) less entertainment facilities, more healthy and well-being conditions, (3) accessible for everybody, especially for vulnerable populations.

The fresh air has to be considered as a primary good and necessity for well-being of everyone, also in pandemic. This is an emergency question. Urban planners, architects, landscape planners, city managers and others have to create conditions for more adaptable public green spaces also in case of mass infections.

\section{Research results}

We can argue that our cities and built environment in long-term need new spatially approaches, spatial organised structure and measures for future development focusing on (1) space increasing of urban nature, green spaces and urban parks in cities: new innovative approaches for urban planning to include green structures (for example, integrating greenways into transportation corridors (Kleinschroth \& Kowarik, 2020); (2) including principles and accessibility of natural spaces and parks in the cities during the pandemic (especially for vulnerable populations); (3) innovative approach for design of urban nature, green spaces and urban parks (more healthy, more adaptable for use also in pandemic). Those 3 principles have to be

embankment, Park Muzeon, Sparrow Hills, Hermitage Garden, Park Zaryadye, Museum-reserve "Tsaritsyno", Museum-reserve "Kolomenskoye", Estate Altufevo, Vlakhernskoye Estate, Vorontsovo Estate, Father Frost's Estate, Izmailovo Estate, Kuskovo estate, Estate Lyublino, Ostankino Estate, Moscow Zoo.

2 Procedure for conducting an experiment to provide the possibility of the citizens to leave the place of residence (stay) for the purpose of walking and exercising in physical culture and sport. Appendix 7-8. Decree of the Mayor of Moscow of 27.05.2020 N 61-UM "On amendments to the decree of the Mayor of Moscow of March 5, 2020 N 12-UM"

${ }^{3}$ Forbidden to use for the purpose of walking and physical education and sports the territory of Zaryadye park. 
put as basic for urban and spatial planning, management and development of natural spaces and urban parks in the cities to reduce the effect of the pandemic on people well-being.

\section{Conclusion}

More nature and green spaces in the cities we need. The urban nature, urban parks and green areas in long-term have to be more adaptable as a green infrastructure for human well-being. Urban planning approaches, standards and technical norms have to be adapted in case of pandemic to permit to have more sustainable urban structures, to have inclusive urban space also in pandemic. Approaches for design of green spaces and urban nature norms and standards for planning and design of public spaces, in particularly green spaces and urban nature need to be redefined in direction of sustainability and resilience in pandemic also, taking into account local conditions and special unique characteristics of the territory.

\section{References}

Barbier, E. B., \& Burgess, J. C. (2020). Sustainability and development after COVID-19. World Development, $135,105082$.

Cacioppo, J. T., Hawkley, L. C., \& Thisted, R. A. (2010). Perceived social isolation makes me sad: 5-year crosslagged analyses of loneliness and depressive symptomatology in the Chicago Health, Aging, and Social Relations Study. Psychology and aging, 25(2), 453.

Danilina, N.V., \& Vlasov, D.N. (2020). "Healthy" city as a basic concept of territorial development. Ecology of urbanized territories, (2). // Данилина, Н. В., \& Власов, Д. Н. (2020). «Здоровый» город как базовая концепция территориального развития. Экология урбанизированных территорий, (2). DOI: 10.24411/1816-1863-2020-12112

Decree of the Mayor of Moscow, 05.03.2020, No.12-um // Указ Мэра Москвы от 5 марта 2020 г. N 12-УМ.

GA, U. (2015). Transforming our world: the 2030 Agenda for Sustainable Development. Division for Sustainable Development Goals: New York, NY, USA.

Hamidi, S., Sabouri, S., \& Ewing, R. (2020). Does density aggravate the COVID-19 pandemic? Early findings and lessons for planners. Journal of the American Planning Association, 1-15.

Hanzl, M. (2020). Urban forms and green infrastructure-the implications for public health during the COVID19 pandemic. Cities \& Health, 1-5.

Hawkley, L. C., \& Cacioppo, J. T. (2010). Loneliness matters: A theoretical and empirical review of consequences and mechanisms. Annals of behavioral medicine, 40(2), 218-227.

Holt-Lunstad, J., Smith, T. B., Baker, M., Harris, T., \& Stephenson, D. (2015). Loneliness and social isolation as risk factors for mortality: a meta-analytic review. Perspectives on psychological science, 10(2), 227-237.

Kleinschroth, F., \& Kowarik, I. (2020). COVID-19 crisis demonstrates the urgent need for urban greenspaces. Frontiers in Ecology and the Environment, 18(6), 318.

Lai, S., Leone, F., \& Zoppi, C. (2020). Covid-19 and spatial planning. TeMA-Journal of Land Use, Mobility and Environment, 231-246.

Lai, K. Y., Webster, C., Kumari, S., \& Sarkar, C. (2020). The nature of cities and the Covid-19 pandemic. Current Opinion in Environmental Sustainability.

Lopez, B., Kennedy, C., \& McPhearson, T. (2020). Parks are Critical Urban Infrastructure: Perception and Use of Urban Green Spaces in NYC During COVID-19. 
Megahed, N. A., \& Ghoneim, E. M. (2020). Antivirus-built environment: Lessons learned from Covid-19 pandemic. Sustainable Cities and Society, 61, 102350.

Odokienko, E.V., \& Maslova, N.V. (2015). The problem of the quality of the microclimate of residential premises. In Natural resource potential, ecology and sustainable development of Russian regions (pp. 78-80) // Одокиенко, Е. В., \& Маслова, Н. В. (2015). Проблема качества микроклимата жилых помещений. In Природноресурсный потенциал, экология и устойчивое развитие регионов России (рр. 78-80).

Owen, D. (2014). Green metropolis. EGEA spa.

Ren, X. (2020). Pandemic and lockdown: a territorial approach to COVID-19 in China, Italy and the United States. Eurasian Geography and Economics, 1-12.

Reshetnikov, V., Mitrokhin, O., Shepetovskaya, N., Belova, E., \& Jakovljevic, M. (2020). Organizational measures aiming to combat COVID-19 in the Russian Federation: the first experience. Expert Review of Pharmacoeconomics \& Outcomes Research.

Rice, W. L., Mateer, T. J., Reigner, N., Newman, P., Lawhon, B., \& Taff, B. D. (2020). Changes in recreational behaviors of outdoor enthusiasts during the COVID-19 pandemic: analysis across urban and rural communities. Journal of Urban Ecology, 6(1), juaa020.

Samuelsson, K., Barthel, S., Colding, J., Macassa, G., \& Giusti, M. (2020). Urban nature as a source of resilience during social distancing amidst the coronavirus pandemic. https://doi.org/10.31219/osf.io/3wx5a

Slater, S. J., Christiana, R. W., \& Gustat, J. (2020). Recommendations for Keeping parks and green space accessible for mental and physical health during COVID-19 and other pandemics. Preventing chronic disease, 17, E59.

Vatin, N.I., \& Samoplyas, T.V. (2004). Ventilation systems for residential premises in apartment buildings // Ватин, Н. И., \& Самопляс, Т. В. (2004). Системы вентиляции жилых помещений многоквартирных домов.

Venter, Z., Barton, D., Gundersen, V., Figari, H., \& Nowell, M. (2020). Urban nature in a time of crisis: recreational use of green space increases during the COVID-19 outbreak in Oslo, Norway. Environmental Research Letters.

Xie, J., Luo, S., Furuya, K., \& Sun, D. (2020). Urban Parks as Green Buffers During the COVID-19 Pandemic. Sustainability, 12(17), 6751.

Zagorskaya, A.I. (2014). Effect of electromagnetic radiation on human health. In RUSSIA YOUNG (pp. 297297) // Загорская, А. И. (2014). Влияние электромагнитных излучений на здоровье человека. In РОССИЯ МОЛОДАЯ (рр. 297-297). 